\title{
Proline metabolism-related gene expression in four potato genotypes in response to drought stress
}

\author{
Y. LIU ${ }^{1,2}$, L. WANG ${ }^{1,3}$, Y. LI $I^{4}$, X. $\mathrm{LI}^{5}$, and J. ZHANG ${ }^{1,4 *}$ \\ Gansu Provincial Key Laboratory of Aridland Crop Science, Gansu Agricultural University, \\ Lanzhou 730070, P.R. China ${ }^{1}$ \\ College of Agronomy, Gansu Agricultural University, Lanzhou 730070, P.R. China ${ }^{2}$ \\ College of Life Science and Technology, Gansu Agricultural University, Lanzhou 730070, P.R. China ${ }^{3}$ \\ College of Horticulture, Gansu Agricultural University, Lanzhou 730070, P R. China ${ }^{4}$ \\ Qingyang Academy of Agricultural Sciences, Qingyang 745000, P.R. China ${ }^{5}$
}

\begin{abstract}
Drought severely limits potato yield. The aim of this work was to study a response of plantlets of four potato genotypes to polyethylene glycol (PEG 6000)-induced drought stress in both physiological and molecular levels. The droughttolerant and drought-sensitive genotypes were identified based on plantlet growth, chlorophyll content, lipid peroxidation, free proline content, and proline metabolism-related gene expressions. We found that PEG-induced stress increased malondialdehyde (MDA) and proline content, and drought-tolerant plantlets exhibited lower MDA and proline content than sensitive genotypes. In addition, PEG up-regulated $\Delta$-1-pyrroline-5-carboxylate synthase (P5CS) and pyrroline5-carboxylate reductase $(P 5 C R)$ gene expressions and down-regulated pyrroline dehydrogenase $(P D H)$ and $\triangle$-1-pyrroline-5-carboxylate dehydrogenase (P5CDH) gene expressions. Genotype B plantlets exhibited lower $P 5 C S$ and $P 5 C R$ expressions and higher $P D H$ and $P 5 C D H$ expressions compared with the other plantlets. The results suggest that significant cultivar differences among potato plantlets in response to PEG-induced drought stress are exhibited in root length, MDA content, proline accumulation, and proline metabolism-related gene expressions.
\end{abstract}

Additional key words: chlorophyll, in vitro cultivation, malondialdehyde, PEG-induced drought stress, Solanum tuberosum.

\section{Introduction}

Productivity of potatoes in some regions is low because of drought and salt stress (Wang et al. 2005). Until now, only a small amount of drought-tolerant cultivars are cultivated. Nevertheless, the International Potato Center (CIP) in Peru maintains 4354 landraces of potato and 2414 accessions of wild relatives to meet an international requirement for potato genetic resources (Ellis et al. 2015). To locate drought-resistant potato plants for growing in northwestern China, we obtained 119 plantlets from the CIP for assessment. We aimed to analyze in vitro plantlets and to provide a fast, effective approach to study physiological responses to drought stress according to Tewary et al. (2000).
We chose polyethylene glycol (PEG) to induce drought stress, similar to drought found in nature because PEG does not penetrate into plants, and it is able to reduce soil water availability (Larher et al. 1993, Gopal et al. 2008, Rai et al. 2011). We examined physiological and molecular changes in four in vitro grown potato genotypes obtained from the CIP in response to PEG-induced drought stress. The four plantlets were chosen out of 119 due to their growth in northern China ( $>$ A $>C>D)$. The aim was to provide insights into the physiological and molecular differences among drought-tolerant and drought-sensitive potato genotypes. The physiological characteristics chosen were chlorophyll content, malondialdehyde (MDA) content (an important indicator of lipid peroxidation), and proline accumulation, which has been reported to

Submitted 21 December 2018, last revision 17 January 2019, accepted 26 February 2019.

Abbreviations: CIP - International Potato Center; MDA-malondialdehyde; MS - Murashige and Skoog; OAT - ornithine-aminotransferase; P5CDH - $\Delta$-1-pyrroline-5-carboxylate dehydrogenase; P5CR - pyrroline-5-carboxylate reductase; P5CS - $\Delta$-1-pyrroline-5-carboxylate synthase; PDH - pyrroline dehydrogenase; PEG - polyethylene glycol; qPCR - quantitative PCR.

Acknowledgements: This research was financially supported by the National Natural Science Foundation of China (grant Nos. 31601356 and 31860398), the Gansu Science Foundation for Distinguished Young Scholars (17JR5RA138), and the Program for Longyuan Youth Innovation Talents of Gansu Province and Fuxi Talent Project of Gansu Agricultural University (Gaufx-02Y04).

* Corresponding author; e-mail: zhangjunlian77@163.com 
correlate closely with drought and salinity stress in plants (Delauney and Verma 1993, Gupta and Huang 2014). The free proline content is regulated by the reciprocal action of its biosynthesis and degradation. Glutamate and ornithine are two different proline precursors that are converted to glutamic- $\gamma$-semialdehyde, catalyzed by the rate-limiting enzyme $\Delta 1$-pyrroline-5-carboxylate synthetase (P5CS), and ornithine $\delta$-aminotransferase (OAT), respectively (Spoljarevic et al. 2011). Glutamic- $\gamma$-semialdehyde is spontaneously converted to pyrroline-5-carboxylate (P5C), which is further converted to proline catalyzed by $\mathrm{P} 5 \mathrm{C}$ reductase (P5CR). Two enzymes proline dehydrogenase $(\mathrm{PDH})$ and $\mathrm{P} 5 \mathrm{C}$ dehydrogenase $(\mathrm{P} 5 \mathrm{CDH})$ are responsible for proline degradation (Xue et al. 2009). Therefore, the molecular measurements chosen were expression of proline biosynthesis-related genes.

\section{Materials and methods}

Plants and cultivation: The CIP391047.34, CIP385499.11, CIP394611.112, and CIP391919.3 are the four tetraploid potato (Solanum tuberosum L.) genotypes, from the CIP, that are referenced here as plant genotypes $\mathrm{A}, \mathrm{B}, \mathrm{C}$, and $\mathrm{D}$, respectively. They were propagated in vitro on a solidified Murashige and Skoog (1962; MS) medium containing $3 \%(\mathrm{~m} / \mathrm{v})$ sucrose and $0.5 \%(\mathrm{~m} / \mathrm{v})$ agar ( $\mathrm{pH} 5.8 \pm 1)$. Plantlets ( $1 \mathrm{~cm}$ long) containing axillary buds were cultured in $150 \mathrm{~cm}^{3}$ triangular flasks and grown at a 16-h photoperiod, an irradiance of $200 \mu \mathrm{mol} \mathrm{m} \mathrm{m}^{-2} \mathrm{~s}^{-1}$ (white fluorescent lamps), and a temperature of $23 \pm 2{ }^{\circ} \mathrm{C}$. Plantlets with at least one leaf and one axillary bud were sub-cultured in the MS medium supplemented with 0 (control), 2.5, 5.0, 7.5, $10.0 \%$ (m/v) PEG 6000 to induce water stress. There were six plantlets in each triangular flask and each replication contained seven triangular flasks (three replications). Leaf samples were collected after a 20 -d treatment for analyses.

Chlorophyll content was measured using a method of Wang et al. (2011). The chlorophyll was extracted from the plant tissue using $80 \%(\mathrm{v} / \mathrm{v})$ acetone, then the solution was vigorously shaken for $10 \mathrm{~s}$, and lastly it was stored at $4{ }^{\circ} \mathrm{C}$ overnight. Afterwards, the solution was centrifuged at $10000 \mathrm{~g}$ to remove the debris. Absorbance was determined at 645 and $663 \mathrm{~nm}$ using a spectrophotometer $(U V-2100$, Shimadzu, Kyoto, Japan), and chlorophyll content was calculated according to Arnon et al. (1949).

Lipid peroxidation: Malondialdehyde content, an important indicator of lipid peroxidation, was determined according to Hodges et al. (1999) with a slight modification. Approximately $0.5 \mathrm{~g}$ of fresh leaves was homogenized with a mortar and pestle using $5 \mathrm{~cm}^{3}$ of $20.0 \%(\mathrm{~m} / \mathrm{v})$ trichloroacetic acid. The homogenate was centrifuged at $10000 \mathrm{~g}$ and $4{ }^{\circ} \mathrm{C}$ for $15 \mathrm{~min}$, and 1 $\mathrm{cm}^{3}$ of supernatant was added to $2 \mathrm{~cm}^{3}$ of $0.5 \%(\mathrm{~m} / \mathrm{v})$ thiobarbituric acid containing $20 \%(\mathrm{~m} / \mathrm{v})$ trichloroacetic acid. The samples were heated at $95{ }^{\circ} \mathrm{C}$ in a water bath for $30 \mathrm{~min}$ after vortexing, and the reaction was terminated by quick cooling on ice. Samples were centrifuged at $10000 \mathrm{~g}$ and $4{ }^{\circ} \mathrm{C}$ for $10 \mathrm{~min}$. Absorbance was measured (an $U V-2100$ spectrophotometer) at 450,532, and $600 \mathrm{~nm}$, respectively. Content of MDA was calculated according to Turan and Tripathy (2013).

Proline content: The total proline content was measured by the ninhydrin reaction method (Bates et al. 1973). Approximately $0.1 \mathrm{~g}$ of fresh leaves was homogenized using $3 \%(\mathrm{~m} / \mathrm{v})$ aqueous sulfosalicylic acid, and then the solution was centrifuged at $10000 \mathrm{~g}\left(4^{\circ} \mathrm{C}, 10 \mathrm{~min}\right)$ to remove the debris. Then, $2 \mathrm{~cm}^{3}$ of the supernatant was mixed with $2 \mathrm{~cm}^{3}$ of acid ninhydrin and $2 \mathrm{~cm}^{3}$ of glacial acetic acid in a test tube and incubated at $100{ }^{\circ} \mathrm{C}$ for $1 \mathrm{~h}$. After that, the reaction was terminated in an ice bath. The product was extracted with $4 \mathrm{~cm}^{3}$ of toluene, and absorbance was measured at $520 \mathrm{~nm}$ on a UV-vis spectrophotometer (UV-1601PC, Shimadzu). Proline content was determined from a standard curve.

Extraction of RNA and cDNA synthesis: The total RNA was extracted from the four potato genotypes using a PureLink plant RNA reagent kit (Invitrogen, Carlsbad, CA, USA) as described in the manufacturer's instructions. Then, it was adjusted to $500 \mathrm{ng} \mathrm{mm}^{-3}$ using a Nanodrop ND-1000 spectrophotometer (NanoDropTechnologies, Rockland, DE, USA), Genomic DNA was removed and cDNA was synthesized using the SuperScript ${ }^{\mathrm{II}}$ first-strand synthesis system (Invitrogen).

Real-time quantitative PCR was conducted using the Mx3000P QPCR system (Stratagene, La Jolla, USA) with the MxPro v. 3.00 software. The quantitative PCR (qPCR) was performed three times for each sample in a total reaction volume of $25 \mathrm{~mm}^{3}$ consisting of $100 \mathrm{ng}$ of template cDNA, $0.2 \mu \mathrm{M}$ forward and reserve primers, and $12.5 \mathrm{~mm}^{3}$ of $2 \times$ SYBR Premix Ex Taq (TaKaRa, Dalian, China). The thermal cycling process was as follows: an initial denaturation cycle at $95{ }^{\circ} \mathrm{C}$ for $5 \mathrm{~min}$ followed by 40 cycles at $95{ }^{\circ} \mathrm{C}$ for $5 \mathrm{~s}$, annealing at $60{ }^{\circ} \mathrm{C}$ for $10 \mathrm{~s}$, elongation at $72{ }^{\circ} \mathrm{C}$ for $10 \mathrm{~s}$, and melting curve detection at $65-95^{\circ} \mathrm{C}$. The potato elongation factor-1 (AB061263) was selected as a constitutive control for template normalization. Relative gene expression was calculated using the $2^{-\Delta \Delta C t}$ method (Livak and Schmittgen 2001). Primers are listed in Table 1 Suppl.

Statistical analysis: Data were expressed as means \pm SEs. All data were statistically analyzed through linear regression analysis to determine significant differences among treatments at $P \leq 0.05$ by using the $S P S S$ statistical software (v.17.0, SPSS Inc., Chicago, IL, USA).

\section{Results}

Polyethylene glycol-induced stress hindered the growth of all four plant genotypes regardless of concentration, as seen on day 20 (Table 1 and Fig. 1 Suppl). Linear regression was performed using GraphPad, and both coefficients and 
Table 1. Effect of polyethylene glycol (PEG)-induced stress on the growth of potato plantlets in vitro for $20 \mathrm{~d}$. Means \pm SEs, $n=3$. Values in a column with the same letters are not statistically different at $P \geq 0.05$ by the Duncan test.

\begin{tabular}{cclll}
\hline Genotypes & PEG concentration [\%] & Number of new leaves [plant $\left.{ }^{-1}\right]$ & Number of roots [plant $\left.{ }^{-1}\right]$ & Root length [cm plant $\left.^{-1}\right]$ \\
\hline A & control & $5.33 \pm 0.45 \mathrm{a}$ & $5.00 \pm 0.38 \mathrm{a}$ & $9.83 \pm 0.35 \mathrm{a}$ \\
& 2.5 & $3.00 \pm 0.33 \mathrm{~b}$ & $2.33 \pm 0.21 \mathrm{~b}$ & $5.70 \pm 0.33 \mathrm{~b}$ \\
& 5.0 & $1.33 \pm 0.16 \mathrm{c}$ & $1.67 \pm 0.33 \mathrm{bc}$ & $2.37 \pm 0.14 \mathrm{c}$ \\
& 7.5 & $1.00 \pm 0.23 \mathrm{c}$ & $1.33 \pm 0.19 \mathrm{bc}$ & $1.67 \pm 0.20 \mathrm{~cd}$ \\
$\mathrm{~B}$ & $0.67 \pm 0.13 \mathrm{c}$ & $0.67 \pm 0.12 \mathrm{c}$ & $0.37 \pm 0.11 \mathrm{~d}$ \\
& control & $6.00 \pm 0.37 \mathrm{a}$ & $4.67 \pm 0.51 \mathrm{a}$ & $9.27 \pm 0.42 \mathrm{a}$ \\
& 2.5 & $5.00 \pm 0.56 \mathrm{a}$ & $2.33 \pm 0.36 \mathrm{~b}$ & $6.10 \pm 0.49 \mathrm{~b}$ \\
& 5.0 & $3.33 \pm 0.24 \mathrm{~b}$ & $1.67 \pm 0.15 \mathrm{bc}$ & $5.80 \pm 0.33 \mathrm{~b}$ \\
& 7.5 & $3.00 \pm 0.34 \mathrm{~b}$ & $1.67 \pm 0.22 \mathrm{bc}$ & $6.60 \pm 0.28 \mathrm{~b}$ \\
$\mathrm{C}$ & $2.00 \pm 0.21 \mathrm{c}$ & $0.67 \pm 0.13 \mathrm{c}$ & $0.37 \pm 0.09 \mathrm{c}$ \\
& 10.0 & $5.00 \pm 0.23 \mathrm{a}$ & $4.67 \pm 0.44 \mathrm{a}$ & $6.67 \pm 0.39 \mathrm{a}$ \\
& control & $2.67 \pm 0.36 \mathrm{~b}$ & $1.00 \pm 0.28 \mathrm{~b}$ & $3.68 \pm 0.26 \mathrm{~b}$ \\
& 5.5 & $1.67 \pm 0.27 \mathrm{c}$ & $1.00 \pm 0.11 \mathrm{c}$ & $1.40 \pm 0.30 \mathrm{c}$ \\
& 5.0 & $0.67 \pm 0.15 \mathrm{~d}$ & $0.67 \pm 0.12 \mathrm{c}$ & $0.77 \pm 0.21 \mathrm{~d}$ \\
$\mathrm{D}$ & 7.5 & $0.67 \pm 0.09 \mathrm{~d}$ & $4.00 \pm 0.58 \mathrm{a}$ & $0.27 \pm 0.13 \mathrm{~d}$ \\
& 10.0 & $4.67 \pm 0.48 \mathrm{a}$ & $1.67 \pm 0.29 \mathrm{~b}$ & $6.23 \pm 0.55 \mathrm{a}$ \\
& control & $2.00 \pm 0.32 \mathrm{~b}$ & $1.33 \pm 0.22 \mathrm{c}$ & $3.30 \pm 0.36 \mathrm{~b}$ \\
& 2.5 & $1.33 \pm 0.17 \mathrm{bc}$ & $0.67 \pm 0.15 \mathrm{~cd}$ & $0.47 \pm 0.29 \mathrm{c}$ \\
& 5.0 & $0.67 \pm 0.21 \mathrm{~cd}$ & $0.33 \pm 0.11 \mathrm{~d}$ & $0.10 \pm 0.06 \mathrm{~d}$ \\
\hline
\end{tabular}

intercepts were calculated. Genotypes A, C, and D were severely impacted by PEG-induced stress in comparison to genotype $\mathrm{B}$ when examining the number of new leaves (intercepts $P=0.000623$ ), roots (intercepts $P=0.03$ ), and root length (intercepts $P=0.0152$ ). Overall, it was shown that already $2.5 \%$ PEG-induced stress significantly decreased the number of new leaves, roots, and root lengths compared to the control in all genotypes (Table 1 and Fig. 1 Suppl). Leaf and root growth were greatly affected in all four potato genotypes under 5 and $7.5 \%$ PEG. The maximum root length of plant genotypes A, B, $\mathrm{C}$, and $\mathrm{D}$ were in ranges $1.67-2.37 \mathrm{~cm}, 5.80-6.60 \mathrm{~cm}$, $0.77-1.40 \mathrm{~cm}$, and $0.47-1.07 \mathrm{~cm}$, respectively. All four plant genotypes were seriously injured under $10 \%$ PEGinduced stress. Furthermore, there was no visible rooting of plantlets of C and D genotypes. However, in genotype B, the roots and leaves remained present (Fig.1 Suppl). The results suggest that $\mathrm{B}$ was the most tolerant genotype, whereas D was the most sensitive genotype to PEGinduced stress.

After $20 \mathrm{~d}$ of growth in MS medium, genotype B displayed the highest above-ground fresh mass $(95.37 \mathrm{mg}$ per plant), which was 1.56-times higher than of $\mathrm{A}$, 1.87-times higher than of $\mathrm{C}$, and 2.35-times higher than of D genotypes. The ratios of above-ground and root fresh masses to dry masses were 22.87 and 28.25 in genotype B, respectively, which were roughly 1.2- and 1.5-times higher than in the other genotypes (Table 2 Suppl.). The results suggest that genotype B retained a larger water content than the other plant genotypes during PEG-induced stress (Table 2 Suppl.).
Chlorophyll content in genotype B [0.46 $\mathrm{mg} \mathrm{g}^{-1}$ (f.m.)] was 1.41-times higher than in genotype A, 1.38-times higher than in genotype $\mathrm{C}$, and 1.51-times higher than in genotype $\mathrm{D}$ when grown on the control MS medium. The PEGinduced stress significantly decreased chlorophyll content in all four genotypes $(P<0.05)$. Genotype D showed the most dramatic chlorophyll decrease with reduction ranging from 67.74 to $80.65 \%$, whereas genotype B chlorophyll content decreased only by 36.96 to $52.17 \%$ in comparison to the control (Fig. 1). Chlorophyll content of genotype B was 2.39 - 2.79 (2.5 \% PEG), 2.09 - 2.51 (5 \% PEG), 3.56 - 4.12 (7.5\% PEG), and 2.56 - 3.66 (10\% PEG) times higher than that of other genotypes. These results suggest that genotype B had the best photosynthetic capability among the four plant genotypes examined. Genotype D showed the lowest chlorophyll content $\left[0.06 \mathrm{mg} \mathrm{g}^{-1}\right.$ (f.m.)] at $10 \%$ PEG-induced stress. There were no significant differences in chlorophyll content among different PEG concentrations, which suggests that all plantlets were sensitive to PEG-induced stress, and chlorophyll synthesis could have beeen greatly reduced even when they were exposed to a low PEG concentration.

Content ofMDA was measured as an indicator of membrane damage. In the control plantlets, MDA content was $9.2,4.4,10.2$, and $11.3 \mu \mathrm{mol} \mathrm{g}^{-1}$ (f.m.) for genotypes $\mathrm{A}, \mathrm{B}, \mathrm{C}$, and $\mathrm{D}$, respectively. As PEG-induced stress increased, MDA significantly increased $(P<0.05)$ in genotypes $\mathrm{A}, \mathrm{C}$, and $\mathrm{D}$ with ranges $58-76 \%, 43-89 \%$, and $34-79 \%$. Genotype D showed the highest MDA content of $20.2 \mu \mathrm{mol} \mathrm{g}{ }^{-1}$ (f.m.) under $10 \%$ PEG stress. There was no significant difference in MDA content in 


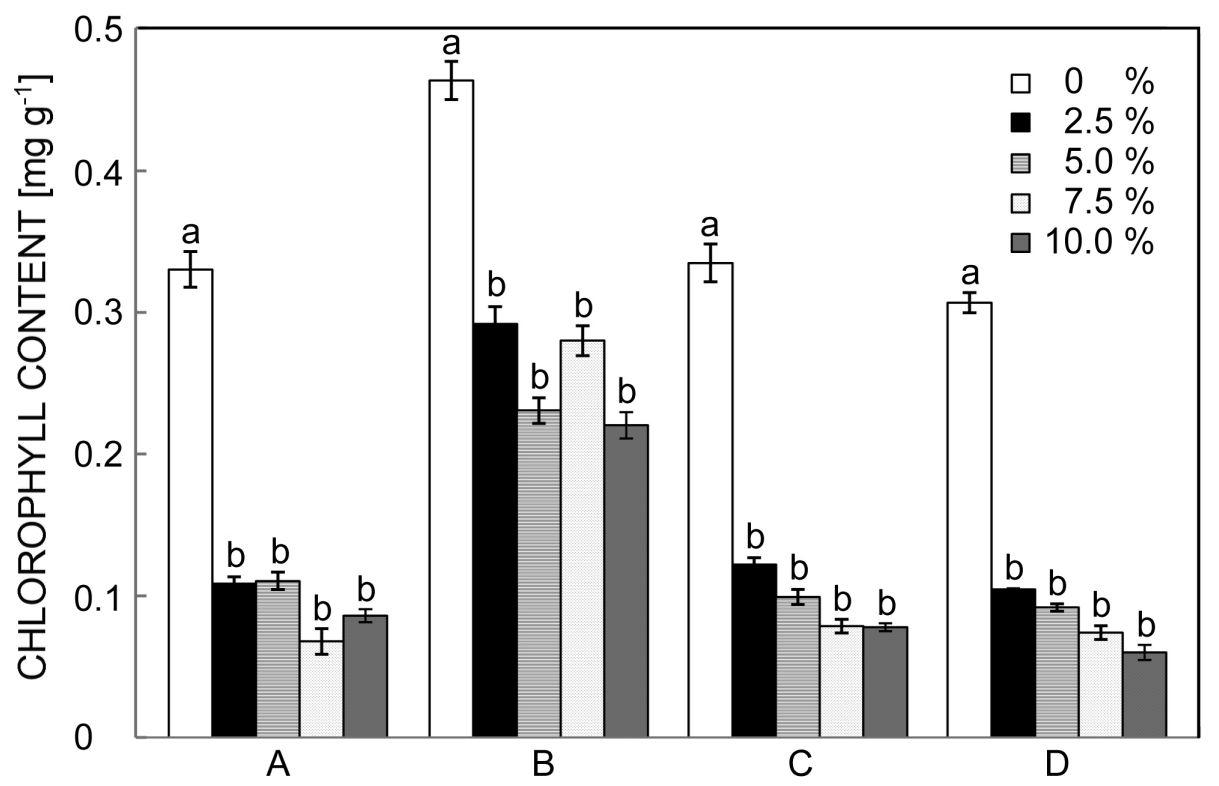

Fig. 1. Chlorophyll content of in vitro grown plantlets of four potato genotypes (A - D) treated with different polyethylene glycol PEG concentrations for $20 \mathrm{~d}$. Means $\pm \mathrm{SEs}, n=3$, different letters indicate significant differences between treatments at $P<0.05$.

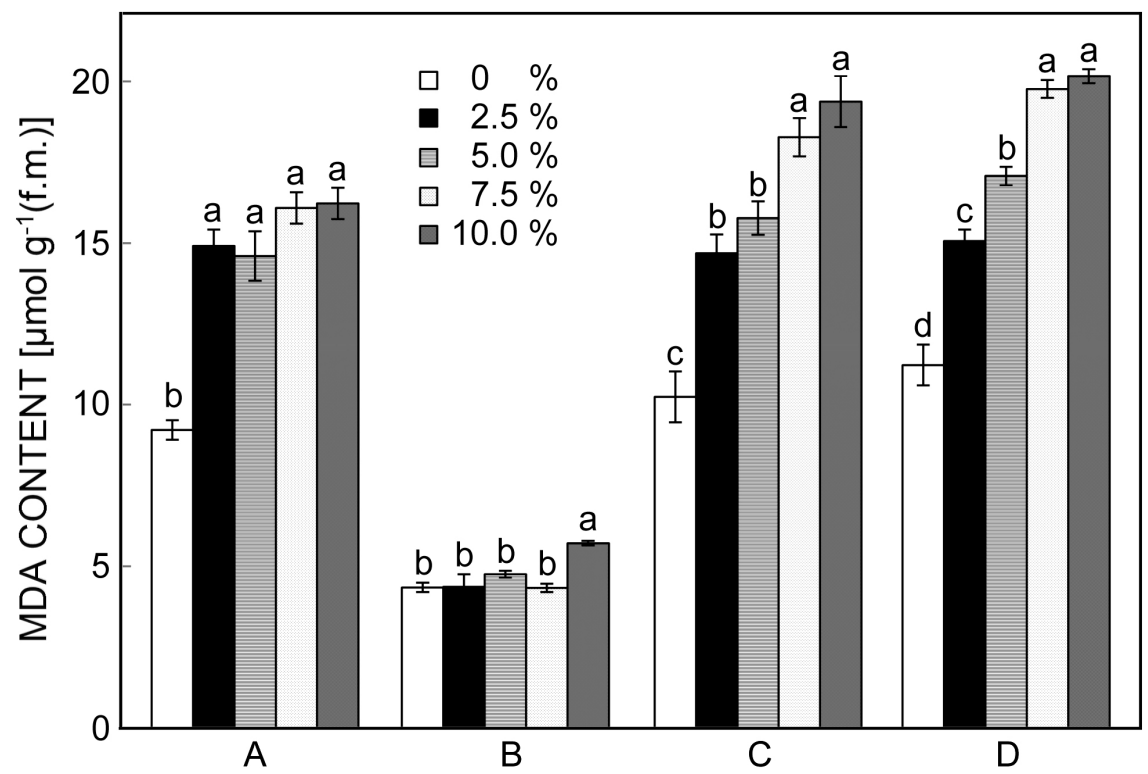

Fig. 2. Effect of different polyethylene glycol concentrations on malondialdehyde (MDA) content in in vitro grown potato plantlets of four genotypes (A - D). Means $\pm \mathrm{SEs}, n=3$, different letters indicate significant differences between treatments at $P<0.05$.

genotype B between the control and $2.5-7.5 \%$ PEG treatment; it increased only by $31 \%$ under $10 \%$ PEG, which was 4-times lower than of genotype D. The results show that the extent of membrane damage in genotype $\mathrm{D}$ was much higher than in the other genotypes, and genotype B showed the lowest degree of membrane damage (Fig. 2).

Distinct differences in free proline content were observed between the four plant genotypes under PEGinduced stress. Proline content of plantlets increased significantly $(P<0.05)$ with the increase in PEG concentration in genotypes $\mathrm{A}, \mathrm{C}$, and $\mathrm{D}$. For genotype $\mathrm{D}$, proline content increased 16-, 38-, 52-, and 57-times compared with the control plantlets under 2.5 to $10 \%$ PEG and reached its highest content of $1.15 \mathrm{mg} \mathrm{g}^{-1}$ (f.m.) under $10 \%$ PEG, which was about 2.5-times higher than in genotype A and 1.9-times higher than in genotype C. Proline content in genotype B significantly increased $(P<0.05)$ under $2.5 \%$ PEG compared to the control, but it was almost the same when the PEG concentration increased to 5 or $7.5 \%$. However, $10 \%$ PEG dramatically increased proline content, but it was still two times lower than that of genotype D (Fig. 3).

The PEG-induced water stress caused a significant increase in P5CS gene expression in the four genotypes, 


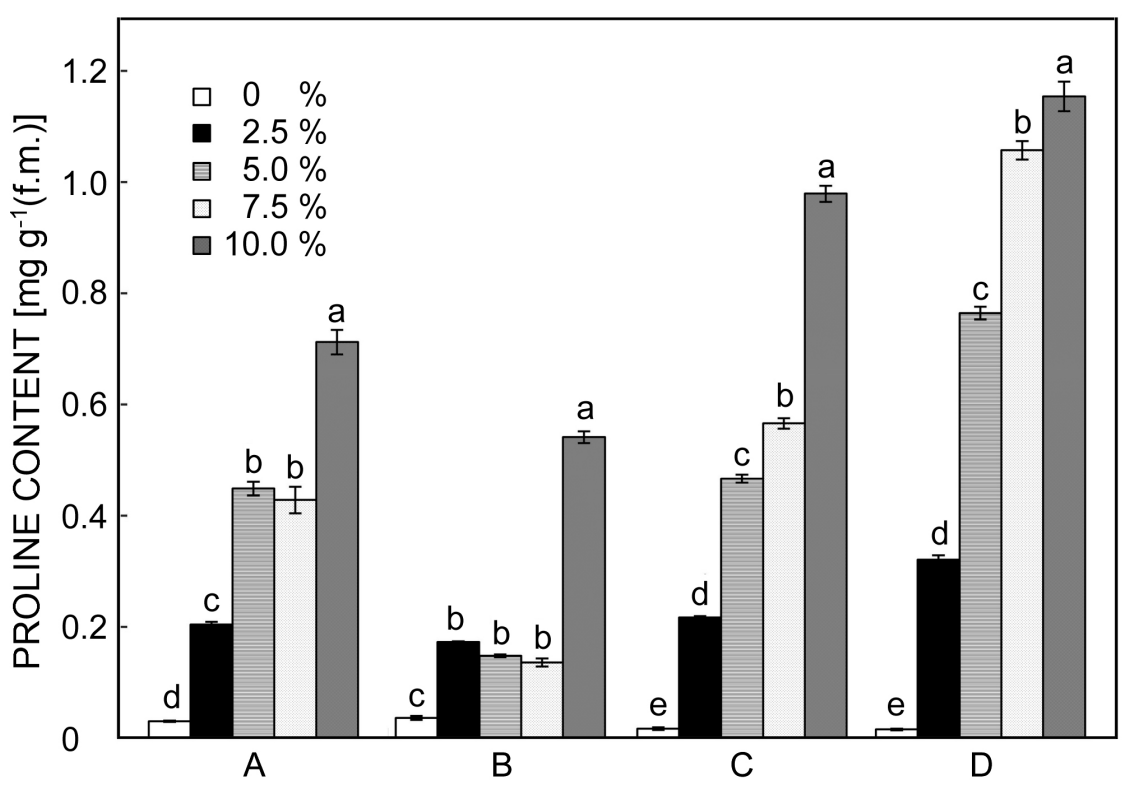

Fig. 3. Effect of different polyethylene glycol concentrations on free proline content of in vitro grown potato plantlets of four genotypes (A - D). Means \pm SEs, $n=3$, different letters indicate significant differences between treatments at $P<0.05$.

and the expression was highest at $10 \%$ PEG. Genotype $\mathrm{B}$ showed the lowest expression and genotype D showed the highest expression (Fig. 4). For A and B, there was no significant difference in $P 5 C S$ gene expression between the control and 2.5 and $5 \%$ PEG-induced stresses, but when PEG concentration increased up to 7.5 and $10 \%, P 5 C S$ gene expression incrased. For genotypes C and D, P5CS was highly expressed already when treated with $2.5 \%$ PEG. The P5CS expression profile correlated with proline accumulation, which suggests that P5CS expression limitated glutamate pathway of proline biosynthesis under PEG-induced stress.

The $O A T$ gene expression significantly increased in genotypes A, C, and D already at 2.5\% PEG-induced stress and in genotype $\mathrm{B}$ at $5 \%$ PEG-induced stress (Fig. 4). The greatest $O A T$ gene expression increase was observed in genotype D under all PEG treatments, which was 1.36 and 2.19 times higher than in genotype A, $2.19-2.94$ times higher than in genotype B and $1.26-1.82$ times higher than in genotype $\mathrm{C}$. The lowest $O A T$ gene expression was found in genotype B under all PEG concentrations.

The P5CR expression profile largely overlapped that of $P 5 C S$. Among the four plant genotypes under water stress, genotype $\mathrm{D}$ showed a dramatic increase of P5CR gene expression under every PEG-induced stress, followed by genotypes C, A, and B (Fig. 4). For the drought-tolerant genotype $\mathrm{B}$, P5CR gene expression increased only 2- to 3.92-times compared to the control, which was much lower than in drought-sensitive genotype $\mathrm{D}$, which had 3.04- to 9.13-times higher P5CR expression than the control.

In contrast, $P D H$ and $P 5 C D H$ gene expressions decreased with the increase in PEG concentration (Fig. 4). Expressions of $P D H$ and $P 5 C D H$ genes significantly decreased in the four plant genotypes treated with $2.5 \%$ PEG, and genotype D showed the greatest decreases in their expressions of 34 and $33 \%$, respectively. $P D H$ and
Expressions of $\mathrm{P} 5 \mathrm{CDH}$ genes dramatically decreased by 78 and $80 \%$ in genotype D when treated with $5 \%$ PEG whereas there was no significant differences for the two gene expressions in genotypes $\mathrm{A}, \mathrm{B}$, and $\mathrm{C}$ between 2.5 and $5 \%$ PEG treatments. Under 7.5 and $10 \%$ PEG, $P D H$ and $P 5 C D H$ gene expressions were relatively lower in genotype $\mathrm{D}$, but higher in genotype $\mathrm{B}$ in comparison to the other genotypes. The results show that $P D H$ and $P 5 C D H$ gene expressions in genotype D were significantly inhibited under all PEG treatments. However, $P D H$ and $P 5 C D H$ expressions in genotype B were not significantly altered when exposed to $2.5-7.5 \%$ PEG.

For plant genotypes A, B, C, and D, proline accumulation displayed a positive correlation to MDA content and to P5CS and P5CR gene expressions under PEG-induced drought stress $(P<0.01$ or $P<0.05)$ whereas $O A T$ gene expression significantly correlated only with proline accumulation $(P<0.01$ or $P<0.05)$ in genotype D (Table 3 Suppl.). Proline accumulation shows a strong, negative correlation with maximum root length and $P D H$ and $P 5 C D H$ gene expressions in the four genotypes under PEG-induced drought stress $(P<0.01$ or $P<0.05)$.

\section{Discussion}

Crops, including potato, can be seriously affected by various biotic and abiotic stresses, and drought belongs to the most important environmental stresses that limits crop productivity (an average crop yield reduction by $50 \%$ or more; Boyer 1982). Therefore, it is essential to promote the development of more drought-tolerant potato genotypes by effectively screening plants, particularly under simulated drought stress. To achieve the goal of attaining food security worldwide, further genetic research needs to be explored, and complex mechanisms related to 


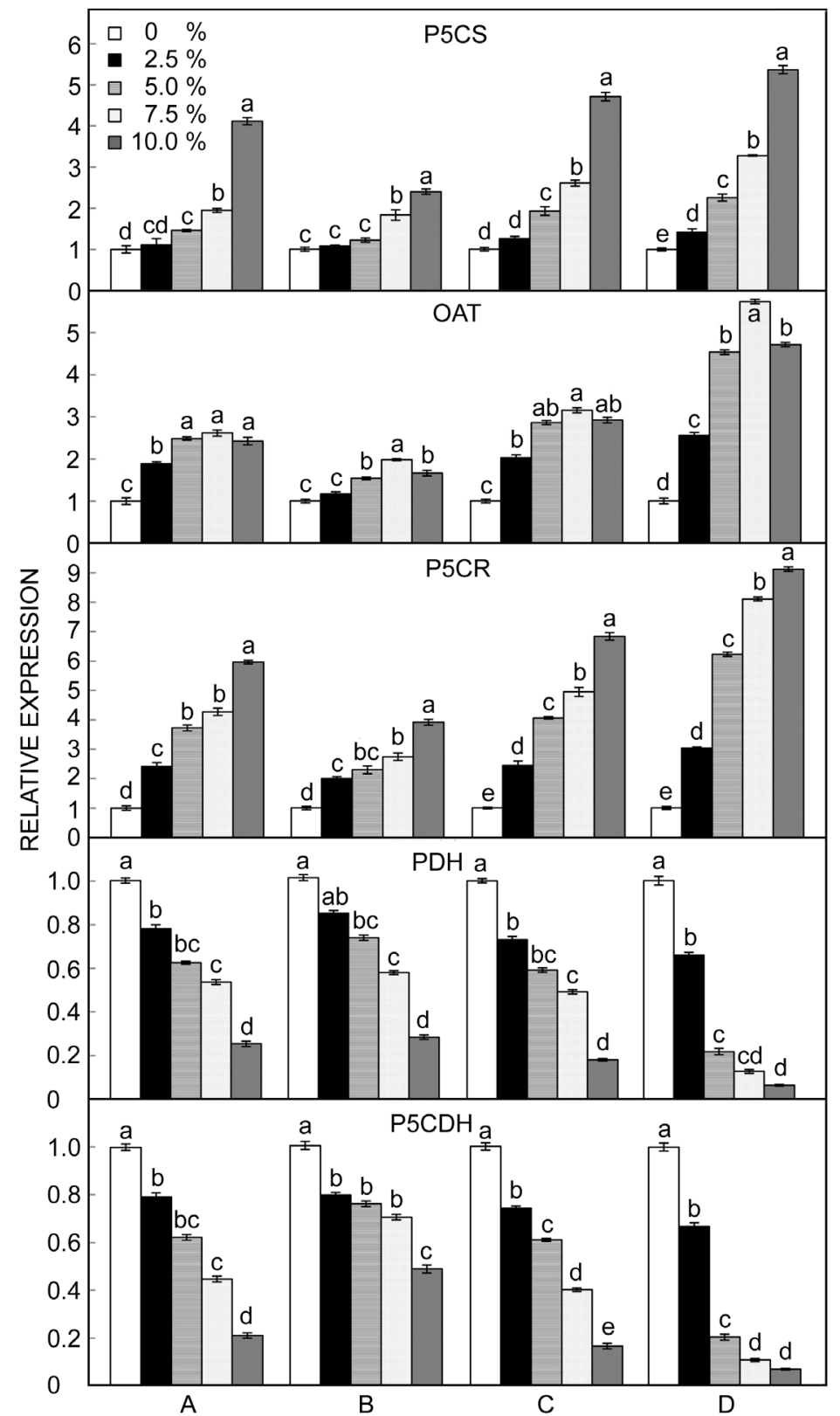

Fig. 4. Effects of different polyetnyıene giycol concentrations on expressions or prolıne syntnesis-related genes in in vitro grown potato plantlets of four genotypes. P5CS - $\triangle$-1-pyrroline-5-carboxylate synthase, OAT - ornithineaminotransferase, P5CR - pyrroline5 -carboxylate reductase, $P D H$ - pyrroline dehydrogenase, $P 5 C D H-\Delta-1$-pyrroline-5-carboxylate dehydrogenase. Means $\pm \mathrm{SEs}, n=3$, different letters indicate significant differences between treatments at $P<0.05$. Meanswere derived from three replicates.

drought-induced stress need to be fully understood.

In this study, plant growth, plant biomass, content of chlorophyll, MDA, and proline, as well as expressions of genes involved in proline biosynthesis were analyzed in four potato genotypes. We applied increasing concentration of PEG to induced stress to the plantlets.

Proline accumulation during stress has been suggested as an indicator of drought-tolerance. To date, the role of proline accumulation in response to drought stress is controversial, and it is unclear whether the proline increase is correlated with drought-tolerance. One theory indicates that proline accumulation under stress enhances salt- or drought-tolerance of the plant, whereas contrasting studies suggest that proline accumulation is a result of osmotic stress, which is a symptom of stress injury rather than an indicator of stress tolerance in plants ( Liu and Zhu 1997, Nayyar and Walia 2003, Demiral and Türkan 2005, Rampino et al. 2006, Wang and Han 2009). In our current research, we found that proline content was related to drought-tolerant or drought-sensitive characteristics. There were significant differences in the amount of proline accumulation in the four plant genotypes under $5.0-10 \%$ PEG. The earliest proline accumulation and highest proline amount were observed in drought-sensitive genotype D 
whereas only a slight increase of proline accumulation was observed in drought-tolerant genotype B in response to 5.0 and $7.5 \%$ PEG-induced stress. Under $10 \%$ PEG, proline content of genotype B significantly increased compared to the control, but it was still much lower than that of genotype D (Fig. 3). The data strongly supports the theory that proline accumulation is a sign of stress-induced plant injures.

To further understand proline biosynthesis mechanisms, the expressions of proline metabolism-related genes were also analyzed. The P5CS and P5CR genes were upregulated with the increase of PEG concentration, but the drought-tolerant genotype B showed only a slight increase under the severe stress. There was a positive correlation between proline content and P5CS and P5CR expressions (Fig. 4 and Table 3 Suppl.). Expression of OAT gene increased under $2.5-7.5 \%$ PEG, but a decrease was observed when the plants were subjected to $10 \%$ PEG. These results suggest that the ornithine pathway not only contributes to proline accumulation, but it may also be involved in glutamate synthesis (Kishor et al. 2014, Kubala et al. 2015).

Proline degradation is the reverse process of proline biosynthesis, which also regulates proline content. Therefore, $P D H$ and $P 5 C D H$, genes related to proline degradation, were inhibited by PEG-induced stress resulting in proline accumulation. There was a negative correlation between proline content and $\mathrm{PDH}$ and $\mathrm{P} 5 \mathrm{CDH}$ gene expressions (Fig. 4 and Table 3 Suppl.). In droughttolerant genotype $\mathrm{B}, \mathrm{PDH}$ and $\mathrm{P} 5 \mathrm{CDH}$ gene expressions were much higher than those found in drought-sensitive genotype D under severe PEG-induced stress. These results suggest that drought-tolerant potato plant genotypes accumulated less proline than the drought-sensitive genotype under PEG-induced stress, which is attributed to the relatively low P5CS and P5CR expressions and high $P D H$ and $P 5 C D H$ expressions. Therefore, downregulating $P 5 C S$ and $P 5 C R$ genes or upregulating $P D H$ and $P 5 C D H$ genes in potato may be beneficial for future development of drought-tolerant genotypes on a large scale.

In our study, proline accumulation positively correlated with MDA content and P5CS and P5CR gene expressions and negatively correlated with maximum root length and $P D H$ and $P 5 C D H$ gene expressions under PEG-induced drought stress. In conclusion, we demonstrated that drought-induced stress alters maximum root length, MDA content, proline accumulation and proline metabolismrelated gene expressions in different genotypes of potato. Our results provide molecular mechanisms and strategies to increase potato yield under drought stress.

\section{References}

Arnon, D. I.: Copper enzymes in isolated chloroplasts, polyphenol oxidase in Beta vulgaris L. - Plant Physiol. 24: 1-15, 1949.

Bates, L.S., Waldren, R.P., Teare, I.D.: Rapid determination of free proline for water-stress studies. - Plant Soil 39: 205-207, 1973.

Boyer, J. S.: Plant productivity and environment. - Science 218: 443-448, 1982.
Delauney, A. J., Verma, D. P. S.: Proline biosynthesis and osmoregulation in plants. - Plant J. 4: 215-223, 1993.

Demiral, T., Türkan, İ.: Comparative lipid peroxidation, antioxidant defense systems and proline content in roots of two rice cultivars differing in salt tolerance. - Environ. exp. Bot. 53: 247-257, 2005.

Ellis, D., Franco, N., Gomez, R., Rossel, G., Manrique, I., Panta, A., Salas, A., Silvestre, R., Vargas, F., Vollmer, R., Zea, B.: The genebank at the International Potato Center: a global asset to help food security. - Amer. J. Potato Res. 92: 186-191, 2015.

Gopal, J., Iwama, K., Jitsuyama, Y.: Effect of water stress mediated through agar on in vitro growth of potato. - In Vitro cell. dev. Biol. Plant. 44: 221-228, 2008.

Gupta, B., Huang, B.: Mechanism of salinity tolerance in plants: physiological, biochemical, and molecular characterization. Int. J. Genomics 2014, 2014.

Hodges, D.M., DeLong, J.M., Forney, C.F., Prange, R.K.: Improving the thiobarbituric acid-reactive-substances assay for estimating lipid peroxidation in plant tissues containing anthocyanin and other interfering compounds. - Planta 207: 604-611, 1999.

Kishor, K., Polavarapu, B., Sreenivasulu, N.: Is proline accumulation per se correlated with stress tolerance or is proline homeostasis a more critical issue? - Plant Cell Environ. 37: 300-311, 2014.

Kubala, S., Wojtyla, Ł., Quinet, M., Lechowska, K., Lutts, S., Garnczarska, M.: Enhanced expression of the proline synthesis gene P5CSA in relation to seed osmopriming improvement of Brassica napus germination under salinity stress. - J. Plant Physiol. 183: 1-12, 2015.

Larher, F., Leport, L., Petrivalsky, M., Chappart, M.: Effectors for the osmoinduced proline response in higher plants. - Plant Physiol. Biochem. 31: 911-922, 1993.

Liu, J., Zhu, J. K.: Proline accumulation and salt-stressinduced gene expression in a salt-hypersensitive mutant of Arabidopsis. - Plant Physiol. 114: 591, 1997.

Livak, K.J., Schmittgen, T D.: Analysis of relative gene expression data using real-time quantitative PCR and the 2 ${ }_{\triangle \triangle C T}$ method. - Methods 25: 402-408, 2001.

Murashige, T., Skoog, F.: A revised medium for rapid growth and bio assays with tobacco tissue cultures. - Physiol. Plant. 15: 473-497, 1962.

Nayyar, H., Walia, D. P.: Water stress induced proline accumulation in contrasting wheat genotypes as affected by calcium and abscisic acid. - Biol. Plant. 46: 275-279, 2003.

Rai, M.K., Kalia, R.K., Singh, R., Gangola, M.P., Dhawan, A.K.: Developing stress tolerant plants through in vitro selection an overview of the recent progress. - Environ. exp. Bot. 71: 89-98, 2011.

Rampino, P., Pataleo, S., Gerardi, C., Mita, G., Perrotta, C.: Drought stress response in wheat: physiological and molecular analysis of resistant and sensitive genotypes. - Plant Cell Environ. 29: 2143-2152, 2006.

Spoljarevic, M., Agic, D., Lisjak, M., Gumze, A., Wilson, I. D., Hancock, J. T., Teklic, T.: The relationship of proline content and metabolism on the productivity of maize plants. - Plant Signal Behav. 6: 251-257, 2011.

Tewary, P., Sharma, A., Raghunath, M., Sarkar, A.: In vitro response of promising mulberry (Morus sp.) genotypes for tolerance to salt and osmotic stresses. - Plant Growth Regul. 30: 17-21, 2000.

Turan, S., Tripathy, B.C.: Salt and genotype impact on antioxidative enzymes and lipid peroxidation in two rice cultivars during de-etiolation. - Protoplasma 250: 209-222, 2013. 
Wang, S.-T., Pan, Y.-Y., Liu, C.-C., Chuang, L.-T., Chen, C.N. N.: Characterization of a green microalga UTEX 22194: effects of photosynthesis and osmotic stress on oil body formation. - Bot. Studies. 52: 305-312, 2011.

Wang, X.-L., Li, F.-M., Jia, Y., Shi, W.-Q.: Increasing potato yields with additional water and increased soil temperature. - Agr. Water. Manage. 78: 181-194, 2005.
Wang, X. S., Han, J. G.: Changes of proline content, activity, and active isoforms of antioxidative enzymes in two alfalfa cultivars under salt stress. - J. integr. Agr. 8: 431-440, 2009.

Xue, X., Liu, A., Hua, X.: Proline accumulation and transcriptional regulation of proline biothesynthesis and degradation in Brassica napus. - BMB Rep. 42: 28-34, 2009. 